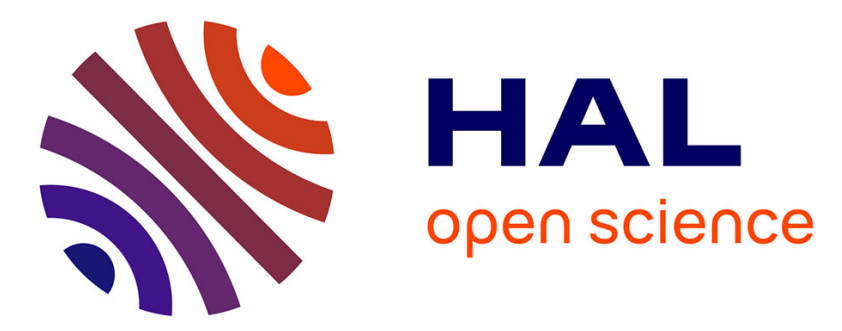

\title{
Reduced total testosterone concentrations in young healthy South Asian men are partly explained by increased insulin resistance but not by altered adiposity. \\ Mousumi Biswas, David Hampton, Atilla Turkes, Robert Newcombe, Aled Rees
}

\section{To cite this version:}

Mousumi Biswas, David Hampton, Atilla Turkes, Robert Newcombe, Aled Rees. Reduced total testosterone concentrations in young healthy South Asian men are partly explained by increased insulin resistance but not by altered adiposity.. Clinical Endocrinology, 2010, 10.1111/j.1365-2265.2010.03824.x . hal-00552607

\section{HAL Id: hal-00552607 https://hal.science/hal-00552607}

Submitted on 6 Jan 2011

HAL is a multi-disciplinary open access archive for the deposit and dissemination of scientific research documents, whether they are published or not. The documents may come from teaching and research institutions in France or abroad, or from public or private research centers.
L'archive ouverte pluridisciplinaire HAL, est destinée au dépôt et à la diffusion de documents scientifiques de niveau recherche, publiés ou non, émanant des établissements d'enseignement et de recherche français ou étrangers, des laboratoires publics ou privés. 


\section{CLINICAL ENDOCRINOLOGY}

\section{Reduced total testosterone concentrations in young healthy South Asian men are partly explained by increased insulin resistance but not by altered adiposity.}

\begin{tabular}{|r|l|}
\hline Journal: & Clinical Endocrinology \\
\hline Manuscript ID: & CEN-2010-000249.R1 \\
\hline Manuscript Type/Office: & 1 Original Article - UK/Europe \\
\hline Date Submitted by the & 18 -Mathor: 2010 \\
\hline Complete List of Authors: & $\begin{array}{l}\text { Biswas, Mousumi; Royal Gwent Hospital, Medicine } \\
\text { Hampton, David; Royal Gwent Hospital, Medical Biochemistry } \\
\text { Turkes, Atilla; University Hospital of Wales, Medical Biochemistry } \\
\text { and Immunology } \\
\text { Newcombe, Robert; Cardiff University, Primary Care and Public } \\
\text { Health } \\
\text { Rees, Aled; Cardiff University, Centre for Endocrine and Diabetes } \\
\text { Sciences }\end{array}$ \\
\hline Key Words: & \begin{tabular}{l} 
Testis, Insulin resistance, Testosterone, Ethnicity \\
\hline
\end{tabular} \\
\hline
\end{tabular}

\section{(s) ScholarONE"


Title: Reduced total testosterone concentrations in young healthy South Asian men are partly explained by increased insulin resistance but not by altered adiposity.

Short title: Testosterone in healthy South Asian males.

Authors: Mousumi Biswas*, David Hamptonף, Atilla Turkes†, Robert G. Newcombe $\ddagger$ and D. Aled Rees**

*Department of Medicine and IMedical Biochemistry, Royal Gwent Hospital, Newport, UK, +Department of Medical Biochemistry and Immunology, University Hospital of Wales, Cardiff, UK, $\ddagger$ Department of Primary Care and Public Health, School of Medicine, Cardiff University, UK, ${ }^{* *}$ Centre for Endocrine and Diabetes Sciences, School of Medicine, Cardiff University, UK

Correspondence: Dr Aled Rees, Centre for Endocrine and Diabetes Sciences, School of Medicine, Cardiff University, UK.

Tel: +44 (0) 2920 742341; Fax: +44 (0)2920 744671; E-mail: reesda@cf.ac.uk

Keywords: Testosterone, insulin resistance, ethnicity

Financial disclosure: Nothing to declare

Word count: 2919 


\section{Summary}

Objective To compare ethnic differences in total, free and bioavailable testosterone amongst young healthy South Asian and Caucasian men.

Design and subjects Cross-sectional study of 134 healthy males (age 20-40 years) of South Asian $(n=67)$ or Caucasian $(n=67)$ origin, recruited from hospital staff and students working in Newport, UK. Subjects were excluded if they had a fasting plasma glucose $>5.9 \mathrm{mmol} / \mathrm{l}$, central obesity (waist circumference $\geq 94 \mathrm{~cm}$ [Caucasian] or $\geq 90 \mathrm{~cm}$ [South Asian]) or significant other disease.

Measurements Fasting plasma glucose, total testosterone (determined by immunoassay and mass spectrometry), albumin, SHBG and insulin were measured. Free and bioavailable testosterone were calculated using Vermeulen's formula and insulin resistance was estimated by HOMA-IR.

Results The South Asians were slightly older $(p=0.04)$, shorter $(p<0.001)$, lighter $(p<0.001)$, more insulin resistant $(p=0.006)$, and had a lower BMI $(p=0.012)$, waist circumference $(p=0.043)$ and SHBG $(p=0.001)$ than the Caucasians. Total testosterone was significantly lower in South Asians (mass spectrometry: geometric mean $16.3 \mathrm{nmol} / \mathrm{l}, 95 \%$ reference interval 9.3 to $28.6 \mathrm{nmol} / \mathrm{l})$ compared with Caucasians (mass spectrometry: geometric mean $18.4 \mathrm{nmol} / \mathrm{l}, 95 \%$ reference interval 10.6 to $31.9 \mathrm{nmol} / \mathrm{l} ; \mathrm{p}=0.015)$ but calculated free and bioavailable testosterone were not different between groups. Adjusting for HOMA-IR, but not BMI or waist circumference, partly attenuated the differences in total testosterone.

Conclusions Total, but not free, testosterone concentrations are lower in healthy South Asian males than in Caucasians. These differences are apparent at a young age and may be partly attributable to alterations in insulin sensitivity. 


\section{Introduction}

Hypogonadism is increasingly recognised as a common and important public health problem, with a prevalence of up to $23 \%$ reported in a recent European study of community-residing men over the age of 40 years. ${ }^{1}$ As a result, measurement of circulating testosterone concentration has become commonplace in primary care as well as in endocrine clinic settings. Approximately $50 \%$ of circulating testosterone is bound to the high-affinity protein, sex hormone binding globulin (SHBG), with the remainder bound to albumin or existing in the free form (2-3\%). ${ }^{2}$ In contrast to SHBG-bound testosterone, free and albumin-bound testosterone is readily available to tissues and is collectively referred to as bioavailable testosterone. ${ }^{3}$ Conditions which alter SHBG levels will thus affect tissue testosterone availability. Since portal insulin levels are a major negative regulator of hepatic SHBG production, diseases of reduced insulin sensitivity such as impaired glucose tolerance and type 2 diabetes may have major effects on testosterone availability. ${ }^{4}$ Predisposition to insulin resistance and type 2 diabetes varies greatly according to ethnicity hence it is plausible that ethnicity itself may impact on testosterone concentration. Previous studies investigating the influence of ethnicity on testosterone levels have found no differences in total testosterone concentrations between subjects of Afro-Caribbean and Caucasian origin ${ }^{5,6}$ or between Caucasians and South East Asians. ${ }^{7}$ In contrast, Heald et al, in their study of predominantly middle-aged men living in Manchester, reported significantly reduced total and free testosterone concentrations in South Asians compared with their Caucasian counterparts, ${ }^{8}$ yet a subsequent study of predominantly middle-aged Canadian men concluded that inter-ethnicity differences in bioavailable and total testosterone between South Asians and Caucasians were not significant. ${ }^{9}$ It thus remains unclear whether testosterone concentrations are lowered or not in South Asian men and, if they are, when and by which mechanisms these differences emerge. In light of this uncertainty, we set out to compare ethnic differences in total, calculated free and bioavailable testosterone in a local population of young healthy South Asian and Caucasian men, and sought to explore which biological correlates might explain any variation observed. 


\section{Study design and methods}

\section{Study participants}

The study comprised a population of apparently healthy male volunteers, aged 20-40 years and recruited from the medical student and hospital staff population at the Royal Gwent Hospital, Newport. Ethnicity was self-reported, with Caucasians defined as White British or White Europeans and South Asians defined as Bangladeshi, Indian, Nepalese, Pakistani or Sri-Lankan. Subjects were excluded if they were affected by a current or previous history of chronic obstructive airways disease, depression, diabetes, heart, renal or liver disease, cancer, inflammatory joint or bowel disease, pituitary, thyroid, adrenal or testicular disease. Subjects who had previously received or who were currently taking medications which might affect gonadal function, including anabolic steroids, testosterone, corticosteroids, ketoconazole and spironolactone were excluded. Those subjects working night shifts were also excluded as were those admitting to an alcohol intake in excess of 3-4 units per day. The study was approved by the local research ethics committee and all subjects provided written informed consent prior to study commencement.

\section{Study measurements}

Subjects attended the diabetes centre at the Royal Gwent Hospital after an overnight fast where blood samples were drawn for measurement of total testosterone, sex hormone binding globulin (SHBG), albumin, glucose and insulin. Subjects whose fasting plasma glucose levels were greater than $5.9 \mathrm{mmol} / \mathrm{l}$ were excluded from participation and offered a $75 \mathrm{~g}$ oral glucose tolerance test. Blood samples were centrifuged within 1 hour and aliquots of plasma or serum were frozen at $-80^{\circ} \mathrm{C}$ until analysis, at a maximum of 6 months post-sampling. Body weight (in light clothing without shoes) was measured to the nearest $0.5 \mathrm{~kg}$ on a balance beam scale and body height was measured to the nearest $0.5 \mathrm{~cm}$ using a stadiometer. Body mass index (BMI) was calculated as weight $(\mathrm{kg})$ 4 


\section{Assays}

Total testosterone was measured using the Abbott Architect ${ }^{\mathrm{TM}}$ immunoassay system (REF 7K73, Abbott Diagnostics, Maidenhead, UK). An internal quality sample containing $17.6 \mathrm{nmol} / \mathrm{l}$ testosterone was used for the assessment of imprecision. Inter-assay coefficient of variation (CV) was $2.8 \%(n=20)$. Testosterone immunoassays have adequate specificity for the measurement of testosterone in normal male samples. ${ }^{13}$ However, due to the interference of matrix components of the sample and/or cross reaction with structurally related steroids there is considerable potential for inaccuracy in testosterone measurement in children, females and men with androgen deficiency. ${ }^{14,15}$ Consequently, total testosterone was also assayed using Ultra Performance Liquid Chromatographymass spectrometry/mass spectrometry (tandem-MS). This assay has been extensively validated against gas chromatography-mass spectrometry (GC-MS) (widely considered to be the 'gold standard' for steroid hormone analysis) and employed GC-MS targeted serum standards. The tandem-MS instrument used was a Quattro $^{\mathrm{TM}}$ Premier XE triple quadropole tandem mass spectrometer (Waters Ltd, Watford, UK) operating with positive ion electrospray mode. The liquid chromatography system was a Waters ${ }^{\mathrm{TM}}$ Acquity Ultra Performance Liquid Chromatography (UPLC) system coupled with an Acquity UPLC ${ }^{\circledR}$ BEH C18, 1,7 $\mu \mathrm{m}, 2.1 \times 50 \mathrm{~mm}$ column. The limit of quantification of the assay was $0.2 \mathrm{nmol} / \mathrm{l}$, with excellent agreement between tandem-MS and GCMS results $\left(r^{2}=0.9903\right)$. Precision of this method was assessed in quality control samples containing varying (low, medium and high) concentrations of testosterone. Determination of these samples by 
tandem-MS revealed that the intra- $(n=12)$ and inter-assay $(n=22)$ coefficients of variation were 4.6, 3.7, $2.5 \%$ and 5.7, 4.3, 3.0\%, respectively. Serum albumin was measured using the Abbott Architect Albumin BCP'M assay, [REF 7D54] (total CV $1.4 \%$ at $37 \mathrm{~g} / \mathrm{l}$ albumin). SHBG was measured with the Abbott Architect ${ }^{\mathrm{TM}}$ SHBG immunoassay, [REF8K26] (total CV $5.65 \%$ at a concentration of 24.5 nmol/I). Fasting plasma glucose was measured using the Architect Aeroset System ${ }^{\mathrm{TM}}$, [REF 3L82] (total CV 1.7\%). Fasting insulin was measured with the Abbott Architect ${ }^{\mathrm{TM}}$ insulin immunoassay, [REF 8K41] which has a precision of $\leq 7 \% \mathrm{CV}$ and cross-reactivity with proinsulin of $\leq 0.1 \%$ for a concentration of $10^{6} \mathrm{pg} / \mathrm{ml}$. Insulin resistance was estimated using the homeostasis model assessment method (HOMA-IR) calculated by the formula: (fasting glucose [mmol/I] $x$ fasting insulin $[\mathrm{mIU} / \mathrm{I}]) / 22.5{ }^{16}$ Free testosterone and bioavailable testosterone were calculated using the method of Vermuelen et al. which correlates well with free testosterone measured by equilibrium dialysis and bioavailable testosterone measured following ammonium sulphate precipitation across a broad range of total testosterone values. ${ }^{17}$ Sample sizes were determined using the recommendations of Virtanen et al., who have previously demonstrated that a sample size of $60-80$ is large enough to calculate reference limits and confidence intervals for analyte estimation by a regression method. ${ }^{18}$ More directly relevant to the present study, using a sample size of at least 63 subjects in each group provides $80 \%$ power to detect a shift of 0.5 SD in total testosterone.

\section{Statistical analysis}

Data were analysed using SPSS version 12.0 (Chicago, IL). All variables with the exception of age were log transformed. Results are expressed as geometric means, (obtained by exponentiation of the means of log transformed variables) and 2.5 - 97.5 centiles, which demarcate a $95 \%$ reference interval. Unpaired t-tests were based on log transformed measurements and, as the two ethnic groups showed little evidence of heterogeneity of variance, equal variance was assumed. Univariate correlation for non parametric data used Spearman co-efficients $\rho$ (two-tailed test). Regression 


\section{1}

models were obtained which enabled adjustment for differences in log transformed total testosterone, free testosterone and bioavailable testosterone with differences in age, HOMA-IR, and/or waist circumference or BMI. A p-value of $<0.05$ was regarded as statistically significant.

\section{Results}

A total of 140 (72 South Asian and 68 Caucasian), 20-40 year old males were initially recruited. Five South Asian men were excluded as their fasting plasma glucose was $>5.9 \mathrm{mmol} / \mathrm{l}$. Two of these were subsequently found to have type 2 diabetes, one had normal glucose tolerance and two declined further investigation. One Caucasian male was excluded due to an incidental finding of type 1 diabetes and coeliac disease. A total of 67 men in each ethnic group were thus included in the final analysis. The characteristics of the study subjects are presented in Table 1 . The South Asians were slightly older than the Caucasians (mean age 30.7 , SD 4.8 vs. 28.9, SD 5.2, $p=0.04$ ), shorter $(p<0.001$ ) and lighter $(p<0.001)$ than their Caucasian counterparts, and had a lower BMI $(p=0.012)$ and waist circumference $(p=0.043)$. Furthermore, despite excluding subjects with known dysglycaemia and significant abdominal obesity, South Asians had a higher fasting plasma glucose $(p=0.019)$ and were more insulin resistant (HOMA-IR, $p=0.006$ ) than the Caucasians. In keeping with this, SHBG levels were significantly lower in South Asians $(p=0.001)$.

\section{Testosterone concentrations by ethnicity}

Mean total testosterone concentration measured by immunoassay was significantly lower in South Asians (geometric mean $18.1 \mathrm{nmol} / \mathrm{l}, 95 \%$ reference interval 9.7 to $33.8 \mathrm{nmol} / \mathrm{l}$ ) than in Caucasians (geometric mean $20.7 \mathrm{nmol} / \mathrm{l}, 95 \%$ reference interval 11.9 to $36.0 \mathrm{nmol} / \mathrm{l}, \mathrm{p}=0.011$ ). Mean total testosterone measured by mass spectrometry was also significantly lower in South Asians (geometric mean $16.3 \mathrm{nmol} / \mathrm{l}, 95 \%$ reference interval 9.3 to $28.6 \mathrm{nmol} / \mathrm{l}$ ) than in Caucasians (geometric mean 
$18.4 \mathrm{nmol} / \mathrm{l}, 95 \%$ reference interval 10.6 to $31.9 \mathrm{nmol} / \mathrm{l}, \mathrm{p}=0.015)$. In contrast, calculated free testosterone concentration (South Asian geometric mean $0.43 \mathrm{nmol} / \mathrm{l}, 95 \%$ reference interval 0.24 to $0.77 \mathrm{nmol} / \mathrm{l}$; Caucasian geometric mean $0.44 \mathrm{nmol} / \mathrm{l}, 95 \%$ reference interval 0.26 to $0.74 \mathrm{nmol} / \mathrm{l}$ ) and bioavailable testosterone concentration (South Asian geometric mean $10.1 \mathrm{nmol} / \mathrm{l}$, 95\% reference interval 5.2-19.7, Caucasian geometric mean $10.9 \mathrm{nmol} / \mathrm{l}, 95 \%$ reference interval 6.3 to $18.7 \mathrm{nmol} / \mathrm{l}$ ) were not significantly different between the two groups ( $\mathrm{p}=0.73$ and 0.18 respectively).

Relationship of total testosterone concentrations with insulin sensitivity and adiposity according to ethnicity

In South Asians, there were weak inverse correlations between total testosterone measured by immunoassay and BMI $(\rho-0.347, p=0.004)$, waist circumference $(\rho-0.301, p=0.013)$ and HOMA-IR $(\rho$ -0.309, $p=0.011$ ). Similarly, there were was a weak inverse correlation between total testosterone measured by mass spectrometry and HOMA-IR $(\rho-0.334, p=0.006)$; however an inverse correlation with BMI ( $\rho-0.229)$ and waist circumference $(\rho-0.209)$ did not quite achieve significance $(p=0.064$ and 0.092 respectively).

In Caucasians, weak inverse correlations were also noted between total testosterone measured by immunoassay and BMI $(\rho-0.258, p=0.035)$, weight $(\rho-0.243, p=0.048)$, waist circumference $(\rho$ 0.373, $p=0.002$ ) and HOMA-IR ( $\rho-0.368, p=0.002)$. A similar inverse correlation was noted between total testosterone measured by mass spectrometry and BMI $(\rho-0.356, p=0.003)$, weight $(\rho-0.306$, $p=0.012)$, waist circumference $(\rho-0.395, p=0.001)$ and HOMA-IR $(\rho-0.414, p=0.001)$.

\section{Multiple linear regression analysis}

Regression models were obtained to adjust differences in log-transformed total testosterone between South Asians and Caucasians for concomitant differences in age, HOMA-IR and/or BMI or 8 
waist circumference (table 2). Results for total testosterone measured by immunoassay or mass spectrometry were very similar: the effects of adjusting for HOMA-IR was to attenuate somewhat the shortfall in total testosterone in South Asians. Conversely, the effect of adjusting for waist circumference or BMI was to slightly widen the difference.

\section{Discussion}

This study has shown that total testosterone concentrations were lowered in young South Asian men compared with Caucasians but that differences in calculated free and bioavailable testosterone were not apparent at this age. Regression modelling indicated that these differences were partly attenuated by adjustment for insulin resistance but not by adjustment for adiposity.

Some of the findings in this study are in keeping with those of Heald et al. who showed that total, but also calculated free testosterone concentrations were lower in South Asian males than in their African-Caribbean or Caucasian counterparts. ${ }^{8}$ This contrasts with a more recent study by Zimmerman et al. ${ }^{9}$ who found no differences in total or bioavailable testosterone amongst South Asians and Caucasians. There are a number of factors which may account for these discrepancies. The studies differed in the way in which participants were recruited, in the age range of the subjects studied, and in the methods used to determine total testosterone concentration and its component fractions. Both the Heald and Zimmerman studies recruited their subjects from community sources, respectively in Manchester, UK and British Columbia, Canada. In contrast, we chose a sample of local hospital staff and student volunteers which in theory might have contributed to these different findings. However, we consider this unlikely since all subjects were in self-reported good health and the exclusion criteria were similar to those reported by Zimmerman et al. ${ }^{9}$ Our cohort also differed 
with respect to age; we chose to restrict our analysis to a young population, in order to minimise any confounding influence of age on testosterone levels and to establish whether ethnic differences in testosterone concentrations are apparent under the age of 40 years. This contrasts with the predominantly middle-aged participants in both the Heald (South Asian mean 50.4 years, Caucasian mean 51.4 years) and Zimmerman (total median age 47.9 years) reports. Total testosterone levels may decline slowly with age, but the fall in bioavailable testosterone is more dramatic, ${ }^{19}$ consistent with an increase in $\mathrm{SHBG}^{20}$ hence it is conceivable that the lowered free testosterone in South Asians demonstrated in the Heald et al. study may reflect an ethnic difference which emerges with time. A number of algorithms have been developed to determine free testosterone and these are known to vary widely in their ability to estimate free and bioavailable testosterone levels. ${ }^{21}$ However, since Heald and colleagues also used the Vermuelen method to estimate free testosterone, we cannot attribute the ethnic differences in free testosterone between our and their study to differences in calculation method. Conversely, Zimmerman et al., in keeping with our findings, showed no ethnic differences in bioavailable testosterone. The methods used in each study to measure total testosterone and determine its bioavailable fraction were also different: Heald et al. used a radioimmunoassay to measure total testosterone, Zimmerman et al. used the Siemens Centaur immunoassay whereas both immunoassay and mass spectrometry were used in our study. Mass spectrometry measurement of testosterone offers improved accuracy and sensitivity over immunoassays ${ }^{22}$ which can over- or underestimate total testosterone; ${ }^{13,14}$ indeed, the positive bias of the immunoassay method in our study of approximately $2 \mathrm{nmol} / \mathrm{l}$ is consistent with this observation. Notwithstanding potential concerns surrounding the performance of immunoassays, the consistent results obtained with both methods in the present study suggests that differences in assay methodology may not have contributed significantly to the discrepant study findings. Zimmerman et al. also used a different method to determine bioavailable testosterone, namely ammonium sulphate precipitation. Since calculated bioavailable testosterone levels correlate very 
well with those measured by ammonium sulphate precipitation, ${ }^{17}$ this is unlikely to be an important factor in explaining the different study results.

The analyses suggest that the differences observed in total testosterone between South Asians and Caucasians may be partly explained in terms of a difference in HOMA-IR, although the degree of attenuation was not marked and it is likely that other unknown factors account for residual differences between the 2 ethnic groups. Our findings are in agreement with Heald et al., in which testosterone was found to be independently and negatively associated with fasting insulin. As with their study, although we sought to exclude subjects with significant glucose intolerance, important metabolic differences were identified between the groups, with greater insulin resistance apparent in South Asians despite a lower BMI and waist circumference. This observation is in keeping with many previous studies which have shown that South Asians are more insulin resistant at every level of waist-hip ratio than their European counterparts. ${ }^{23,24,25}$ This inverse relationship between insulin resistance and total testosterone concentration is well recognised ${ }^{26}$ but our results confirm that this develops at a young age. Insulin resistance, obesity and the metabolic syndrome may lower testosterone levels through a number of mechanisms, including increased aromatisation, increased leptin, reduced LH pulsatility, and lowered SHBG concentrations. ${ }^{27,28,29}$ However, although Heald et al. suggested that differences in abdominal obesity might account for the lowered testosterone in South Asians, both in their original study and a second study of South Asian migrants residing in the UK, ${ }^{8,30}$ we did not find evidence for this assertion in our study. Indeed, adjusting for BMI and waist circumference served to widen the difference in total testosterone between the two groups. Our observations may have particular relevance to the setting of type 2 diabetes, since South Asians are known to have an increased risk of developing type 2 diabetes compared to their Caucasian counterparts, and type 2 diabetes is associated with a high prevalence of testosterone deficiency. However, the precise influence of ethnicity on the relationship between testosterone and type 2 diabetes is currently unclear, although observations from the Multi-Ethnic Study of Atherosclerosis 
(MESA) suggest that the inverse association between total testosterone and type 2 diabetes does not differ across ethnic groups. ${ }^{31}$

In summary, we have shown significant differences in total, but not free or bioavailable testosterone concentrations among young healthy South Asian and Caucasian men. Although the $95 \%$ reference intervals for total testosterone in both groups are broadly similar, we believe that our findings are clinically relevant, especially at the lower end of the working range where failure to account for ethnic differences in total testosterone levels may run the risk of misclassifying South Asian individuals as hypogonadal. Further large-scale studies are needed in other populations to confirm or refute our findings, but in the meantime calculated free testosterone may offer a more accurate assessment of androgen status in clinical practice. 


\section{References}

1. Tajar, A., Forti G., O'Neill T.W. et al.,(2010) Characteristics of Secondary, Primary and Compensated Hypogonadism in Aging Men: Evidence from the European Male Ageing Study. Journal of Clinical Endocrinology and Metabolism, 95, 1810-1818.

2. Vermuelen, A., Verdonck, L. (1968) Studies on the binding of testosterone to human plasma. Steroids, 11, 609-635.

3. Pardridge, W.M. (1986) Serum bioavailability of sex steroid hormones. Journal of Clinical Endocrinology and Metabolism, 15, 259-278.

4. Yki-Jarvinen, H., Makimattila, S., Utriainen, T., Rutanen, E.M. (1995) Portal insulin concentrations rather than insulin sensitivity regulate serum sex hormone-binding globulin and insulin-like growth factor binding protein 1 in vivo. Journal of Clinical Endocrinology and Metabolism, 80, 3227-3232.

5. Asbell, S.O., Ramaine, K.C., Montesano, A.T., Zeitzer, K.L., Asbell, M.D., Vijaya-Kumar, S. (2000) Prostate-specific antigen and androgens in African-American and white normal subjects and prostate cancer patients. Journal of the National Medical Association, 92, 445-449.

6. Litman, H.J., Bhasin, S., Link, C.L., Araujo, A.B., McKinlay, J.B. (2006) Serum androgen levels in black, Hispanic and white men. Journal of Clinical Endocrinology and Metabolism, 91, 4326-4334. 
7. Lookingbill, D.P., Demers, L.M., Wang, C., Leung, A., Rittmaster, R.S., Santen, R.J (1991) Clinical and biochemical parameters of androgen action in normal healthy Caucasian versus Chinese subjects, Journal of Clinical Endocrinology and Metabolism ,72, 1242-1248

8. Heald, A., Vision, F., Anderson, S., Cruickshank, K., Laing, I., Gibson, J. (2003) Significant Ethnic variation in total and free testosterone concentration. Clinical Endocrinology, 58, 262-266.

9. Zimmerman, A.C., Buhr, K.A., Lear, S.A., Holmes, D.T. (2009) Age dependent reference intervals for measured bioavailable testosterone on the Siemens Advia Centaur: ethnicity-specific values not necessary for South Asians. Clinical Biochemistry, 42, 922-925.

10. de Moor, P., Joossens, J.V. (1970) An inverse relation between body weight and the activity of the steroid-binding globulin in human plasma. Steroidologia, 1, 129-136.

11. Laaksonen, D. E., Niskanen, L., Punnonen, K. et al. (2004) Testosterone and Sex Hormone-Binding Globulin Predict the Metabolic Syndrome and Diabetes in Middle-Aged Men. Diabetes Care, 27, 1036-1041.

12. International Diabetes Federation (IDF): IDF consensus worldwide definition of the metabolic syndrome April 2005. Available from:

http://idf.org/webdata/docs/Metabolic_syndrome_definition.pdf 
14. Taieb, J., Mathian, B., Millot, F., Patricot, M. et al. (2003) Testosterone measured by 10 immunoassays and by isotope-dilution gas chromatography-mass spectrometry in sera from 116 men, women and children. Clinical Chemistry, 49, 1381-1395.

15. Rosner, W., Auchus, R., Azziz, R., Sluss, P.M., Raff, H. (2007) Utility, limitations and pitfalls in measuring testosterone: an Endocrine society position statement. Journal of Clinical Endocrinology and Metabolism, 92, 405-13.

16. Matthews, D.R., Hosker, J.P., Rudenski, A.S., Naylor, B.A., Treacher, D.F., Turner, R.C. (1985). Homeostasis model assessment: insulin resistance and beta-cell function from fasting plasma glucose and insulin concentrations in man. Diabetologia, 28, 412-419

17. Vermuelen, A., Verdonck, L., Kaufman, J.M. (1999) A critical evaluation of simple methods for the estimation of free testosterone in serum. Journal Clinical Endocrinology and Metabolism, 84, 3666-3672.

18. Virtanen, A., Kairisto, V., Uusipaikka, E. (1998) Regression-based reference limits: determination of sufficient sample size. Clinical Chemistry, 11, 2355-2358. 
19. Gray, A., Feldman, H.A., McKinley, J.B., Longcope, C. (1991) Age, disease, and changing sex hormone levels in middle-age men: results of the Massachusetts Male Aging Study. Journal of Clinical Endocrinology and Metabolism, 73, 1016-1025.

20. Barrett-Connor, E., Von Mühlen, D.G., Kritz-Silverstein, D. (1999) Bioavailable testosterone and depressed mood in older men: the Rancho Bernardo Study. Journal of Clinical Endocrinology and Metabolism, 84, 573-577.

21. de Ronde, W., van der Schouw, Y.T., Pols, H.A.P., Gooren, L.J.G., Muller, M., Grobbee, D.E., de Jong, F.H. (2006) Calculation of bioavailable and free testosterone in men: a comparison of 5 published algorithms. Clinical Chemistry, 52, 1777-1784.

22. Matsumoto, A.M., Bremner, W.J. (2004) Serum Testosterone Assays - Accuracy matters. Journal of Clinical Endocrinology and Metabolism, 89, 520-524.

23. Cruikshank, J.K., Cooper, J., Burnett, M., MacDuff, J., Drubra, U. (1991) Ethnic differences in fasting C-peptide and insulin in relation to glucose tolerance and blood pressure. Lancet, 338, 842847.

24. McKeigue, P.M., Shah, B., Marmott, M.G. (1991) Relationship of central obesity and insulin resistance with high diabetes prevalence and cardiovascular risk in South Asians. Lancet, 337, 382386. 
25. McKeigue, P.M., Pierpont, T., Ferrie, J.E., Marmot, M.G. (1992) Relationship of glucose intolerance to body fat pattern in South Asians and Europeans. Diabetologia, 35,785-791.

26. Grossmann, M., Thomas, M.C., Panagiotopoulos S. et al. (2008) Low testosterone levels are common and associated with insulin resistance in men with diabetes. Journal of Clinical Endocrinology and Metabolism, 93, 1834-1840.

27. Giagulli, V.A., Kaufman, J.M., Vermeulen, A. (1994) Pathogenesis of the decreased androgen levels in obese men Journal of Clinical Endocrinology and Metabolism, 79, 997-1000.

28. Isidori, A.M., Caprio, M., Strollo, F. et al. (1999) Leptin and androgens in male obesity: evidence for leptin contribution to reduced androgen levels. Journal of Clinical Endocrinology and Metabolism, 84, 3673-3680.

29. Lunenfeld, B. (2007) Testosterone deficiency and the metabolic syndrome. Aging Male, 10, 5356.

30. Heald, A., Patel, J., Anderson, S., Vyas, A., Rudenski, A., Hughes, E., Panja, N. et al. (2007) Migration is associated with lower total testosterone, but not free testosterone levels in South Asian men. Clinical Endocrinology, 67, 651-655. 
31. Colangelo, L., Ouyang, P., Liu, K., et al. (2009) Association of endogenous sex hormones with diabetes and impaired fasting glucose in men: multi-ethnic study of atherosclerosis. Diabetes Care, 32, 1049-1051.

\section{Legends for tables}

Table 1. Characteristics of the study subjects.

Results are expressed as geometric means with $95 \%$ reference intervals, and as the ratio of the geometric means with $95 \%$ confidence intervals. ${ }^{*} n=66$ samples for total testosterone measured by mass spectrometry.

Table 2. Back-transformed contrasts between South Asians and Caucasians with adjustment for differences in HOMA-IR, BMI and/or waist circumference. All contrasts are adjusted for residual confounding with the age differences between the groups. Results are expressed as the ratio of the geometric means with $95 \%$ confidence intervals. 
Table 1.

\begin{tabular}{|c|c|c|c|c|}
\hline & $\begin{array}{l}\text { South Asians } \\
(n=67)\end{array}$ & $\begin{array}{l}\text { Caucasians } \\
(n=67)\end{array}$ & $\begin{array}{l}\text { Ratio of } \\
\text { Geometric Means }\end{array}$ & $p$ value \\
\hline Weight (kg) & 70.5 (53.6 to 92.7) & 79.3 (61.7 to 101.9$)$ & 0.889 (0.850 to 0.931$)$ & $<0.001$ \\
\hline Height (m) & 1.74 (1.63 to 1.87 ) & 1.80 (1.66 to 1.96$)$ & 0.968 (0.955 to 0.981$)$ & $<0.001$ \\
\hline Waist (cm) & 82.4 (73.2 to 92.8 ) & 84.2 (74.8 to 94.7 ) & 0.979 (0.959 to 0.999$)$ & 0.043 \\
\hline $\mathrm{BMI}\left(\mathrm{kg} / \mathrm{m}^{2}\right)$ & 23.2 (18.4 to 29.2 ) & 24.4 (19.4 to 30.7 ) & 0.950 (0.912 to 0.989$)$ & 0.012 \\
\hline Fasting glucose $(\mathrm{mmol} / \mathrm{l})$ & 5.11 (4.24 to 6.16$)$ & 4.91 (3.99 to 6.04 ) & 1.042 (1.007 to 1.079 ) & 0.019 \\
\hline Fasting insulin (mIU/l) & 8.46 (2.85 to 25.07$)$ & 6.67 (2.32 to 19.19$)$ & 1.267 (1.051 to 1.528$)$ & 0.013 \\
\hline HOMA-IR & 1.92 (0.61 to 6.07 ) & 1.45 (0.46 to 4.58$)$ & 1.324 (1.083 to 1.618$)$ & 0.006 \\
\hline Albumin (g/l) & 44.5 (40.6 to 48.8 ) & 45.5 (40.7 to 50.9 ) & 0.978 (0.960 to 0.995$)$ & 0.013 \\
\hline SHBG (nmol/I) & 25.6 (12.2 to 53.6 ) & 31.5 (15.7 to 63.0) & 0.812 (0.717 to 0.921$)$ & 0.001 \\
\hline $\begin{array}{l}\text { Total testosterone } \\
\text { (immunoassay) (nmol/l) }\end{array}$ & 18.1 (9.7 to 33.8$)$ & 20.7 (11.9 to 36.0) & 0.874 (0.789 to 0.969$)$ & 0.011 \\
\hline $\begin{array}{l}\text { Total testosterone (mass } \\
\text { spectrometry) (nmol/l) }\end{array}$ & 16.3 (9.3 to 28.6 ) & 18.4 (10.6 to 31.9) & $0.886(0.803$ to 0.977$)$ & 0.015 \\
\hline Free testosterone $(\mathrm{nmol} / \mathrm{l})$ & 0.43 (0.24 to 0.77$)$ & 0.44 (0.26 to 0.74$)$ & 0.984 (0.893 to 1.083$)$ & 0.733 \\
\hline $\begin{array}{l}\text { Bioavailable testosterone } \\
\text { (nmol/l) }\end{array}$ & 10.1 (5.2 to 19.7$)$ & 10.9 (6.3 to 18.7$)$ & 0.930 (0.836 to 1.034$)$ & 0.177 \\
\hline
\end{tabular}


Table 2.

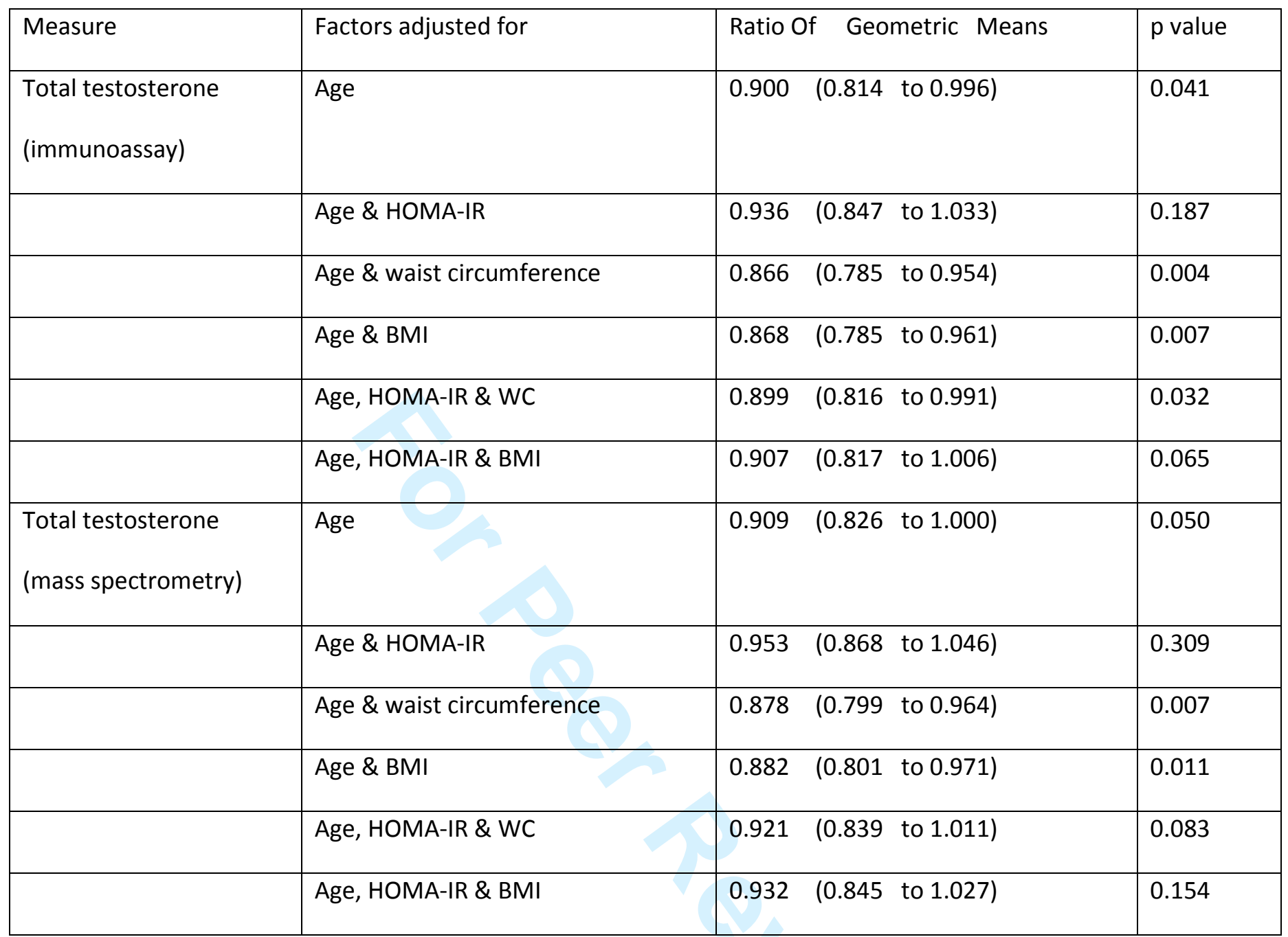

